\title{
Produção da fáfia [Pfaffia glomerata (Spreng.) Pedersen] com cama-de-frango e fósforo incorporados ao solo
}

\author{
VIEIRA, M.C.*; RODRIGUES, W.B.; ZÁRATE, N.A.H.; RAMOS, D.D.; LUCIANO, A.T.; GONÇALVES, W.V.; \\ CARNEVALI, T.O. \\ Universidade Federal da Grande Dourados (UFGD) - FCA, Caixa Postal 533, CEP: 79804-970, Dourados-Brasil \\ *mariavieira@ufgd.edu.br
}

\begin{abstract}
RESUMO: Objetivou-se com este trabalho avaliar o efeito da incorporação ao solo de cama-defrango e de fósforo sobre o crescimento e a produção da fáfia. Os tratamentos foram cinco doses de cama-de-frango semidecomposta $\left(0,5,10,15\right.$ e $\left.20 \mathrm{t} \mathrm{ha}^{-1}\right)$, com e sem o uso de fósforo (200 kg ha- ${ }^{-1}$ de $\mathrm{P}_{2} \mathrm{O}_{5}$, na forma de superfosfato triplo), arranjados em esquema fatorial $5 \times 2$, no delineamento experimental blocos casualizados, com quatro repetições. As alturas das plantas variaram em função das doses da cama-de-frango, sendo maiores $(138,50 \mathrm{~cm})$ sob $20 \mathrm{t} \mathrm{ha}^{-1}$. As produções de massas frescas e secas de folhas, caules e raízes foram influenciadas significativamente pela interação cama-de-frango e fósforo. As maiores produções de massa fresca e seca de folhas (597 kg ha-1 e $100 \mathrm{~kg} \mathrm{ha}^{-1}$, respectivamente) foram obtidas com a dose de $20 \mathrm{t} \mathrm{ha}^{-1}$ de cama-defrango, sem o uso de fósforo. Para caules, as maiores produções de massa fresca e seca (7.757 $\mathrm{kg} \mathrm{ha}^{-1}$ e $2.633 \mathrm{~kg} \mathrm{ha}^{-1}$, respectivamente) foram obtidas com a dose de $20 \mathrm{t} \mathrm{ha}^{-1}$ de cama-defrango, com o uso de fósforo. As maiores produções de massa fresca e seca de raízes $(9.065 \mathrm{~kg}$ ha $^{-1}$ e $377 \mathrm{~kg} \mathrm{ha}^{-1}$, respectivamente) foram obtidas com a dose de $20 \mathrm{t} \mathrm{ha}^{-1}$ de cama-de-frango, sem o uso de fósforo. Os teores médios de N, P e K das folhas foram de 8,60; 0,88 e 4,46 g kg-1, respectivamente. Os teores de Ca e Mg foram máximos (7,56 e 5,12 $\mathrm{g} \mathrm{kg}^{-1}$, respectivamente) com o uso de $20 \mathrm{t} \mathrm{ha}^{-1}$ de cama-de-frango, independente do uso de P. Nas raízes os teores médios de $\mathrm{N}, \mathrm{P}$ e Mg foram de 2,74; 0,27 e 0,96 $\mathrm{g} \mathrm{kg}^{-1}$, respectivamente. $\mathrm{O}$ teor de $\mathrm{K}$ reduziu linearmente com as doses de cama-de-frango e o de Ca foi máximo com o uso de 20 tha-1. Para se obter maiores produções de massas frescas e secas de folhas e raízes, as plantas de fáfia devem ser cultivadas com cama-de-frango $\left(20 \mathrm{t} \mathrm{ha}^{-1}\right)$ incorporada ao solo, sem necessidade de adição de fósforo.
\end{abstract}

Palavras-chave: Ginseng brasileiro, planta medicinal, resíduo orgânico

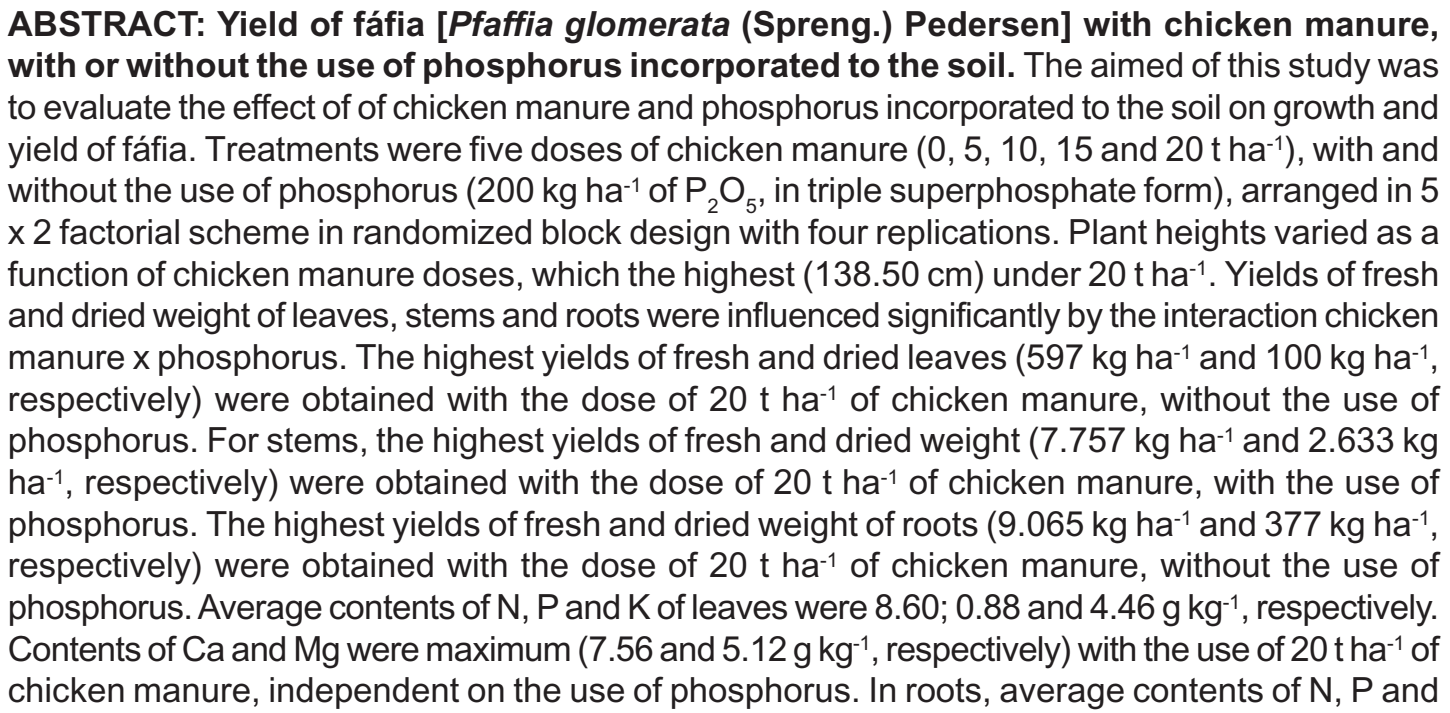

Recebido para publicação: setembro de 2011

Aceito para publicação: março de 2012

Rev. Bras. PI. Med., Botucatu, v.14, n.esp., p.235-241, 2012. 
Mg were $2.74,0.27$ and $0.96 \mathrm{~g} \mathrm{~kg}^{-1}$, respectively. $\mathrm{K}$ content reduced linearly with chicken manure doses and of Ca was maximum with the use of $20 \mathrm{t} \mathrm{ha}^{-1}$. For obtaining the highest yields of fresh and dried weight of leaves and roots, the fáfia plants must be grown with chicken manure (20 tha-1) incorporated to the soil within the use of phosphorus.

Key words: Brazilian ginseng, medicinal plant, organic residue

\section{INTRODUÇÃO}

A fáfia [Pfaffia glomerata (Spreng.) Pedersen, Amaranthaceae] é conhecida como ginseng brasileiro e ginseng do pantanal, por ser considerada sucessora do ginseng verdadeiro (Panax ginseng C.A. Meyer) (Nascimento et al., 2007). A partir de vários estudos sobre as atividades farmacológicas dos compostos presentes nas raízes da fáfia aumentou o interesse comercial, principalmente em relação à sua importância medicinal e econômica. As suas raízes e folhas têm propriedades tranqüilizantes; antireumáticas; antidiarréicas; antiinflamatórias; febrífugas; cicatrizantes internas e externas; antihemorroídícas; melhoradoras da visão e da memória e para o tratamento de distúrbios gástricos, artrite, artrose, anemia, astenia e dores (Silva Júnior \& Osaida, 2005). Em razão disso, tem ocorrido intensa exploração predatória das reservas naturais dessa espécie, portanto, justifica-se que sejam elaborados planos de manejo ou projetos de cultivo (Correa Júnior et al., 2008).

A distribuição geográfica da fáfia é ampla, ocupando condições climáticas e edáficas diferentes, resultando em populações com grande variabilidade genética (Magalhães, 2000). Barboza et al. (2010) encontraram na literatura que a fáfia ocorre em todo - Brasil e países limítrofes, com precipitação pluviométrica entre 1200 a $1500 \mathrm{~mm}$ anuais e altitudes de até $1000 \mathrm{~m}$. É frequente no Cerrado e outros biomas do Mato Grosso do Sul, incluindo o Pantanal, nas margens e ilhas do Rio Paraná, Paranapanema e Ivaí, entre São Paulo, Mato Grosso do Sul e Paraná. Está adaptada aos ciclos de cheia e seca dessas áreas, apresentando plasticidade às mudanças ambientais, que podem facilitar sua exploração e cultivo. Por isso, é natural o grande número de formas e variedades dentro da espécie, pela ampla distribuição geográfica, ocupando condições edafoclimáticas distintas.

Os solos com vegetação de Cerrado, geralmente, possuem elevada acidez e teor de alumínio trocável e deficiência de fósforo, cálcio e magnésio, características essas que são empecilhos ao sucesso das produções agrícolas nesses solos (Souza \& Lobato, 2004). Para esses solos, o pH recomendado fica em torno de 6,0 a 7,0, ocorrendo assim, melhor absorção de $\mathrm{P}$ pelas culturas (Novais \& Smyth, 1999). O P faz parte de compostos essenciais ao metabolismo vegetal, que participam de fenômenos importantes como respiração, fotossíntese e comunicação genética; estimula o crescimento e é fator essencial à formação das raízes. Além disso, auxilia na formação e fecundação das flores, fixação dos frutos e formação das sementes (Taiz \& Zeiger, 2004). A importância do fósforo para o crescimento das plantas está relacionada à síntese de proteínas e ação no processo de absorção iônica (Malavolta, 2006). Assim, o fósforo favorece o desenvolvimento do sistema radicular, aumentando a absorção de água e nutrientes.

No Estado de Mato Grosso do Sul, por haver grande expansão da avicultura de corte, há disponibilidade de volume e massa expressiva de cama-de-frango semidecomposta, que é aproveitada como fonte de resíduo orgânico para o cultivo de diversas espécies vegetais. Só na região da Grande Dourados são mais de 430 aviários em produção que disponibilizam em torno de $150 \mathrm{t}_{\text {ano- }}^{-1}$ de cama-defrango semidecomposta (Graciano et al., 2006). A adição de resíduos orgânicos ao solo promove muitos efeitos benéficos, tais como a melhoria das propriedades físicas, favorecendo a aeração e a capacidade de infiltração e armazenamento de água, permitindo assim, maior penetração e distribuição do sistema radicular. Atua também de maneira positiva em relação às propriedades químicas do solo, onde age na melhoria da capacidade de troca de cátions, na redução do alumínio trocável, aumento de macro e micronutrientes disponíveis para as plantas e na fixação de fosfato (Kiehl, 2008).

Barboza et al. (2006), ao avaliarem o desenvolvimento e a produção de biomassa de Tropaeolum majus $L$. em função de fósforo e de camade-frango semi-decomposta observaram que as mais altas produções de frutos frescos $\left(2.739 .38 \mathrm{~kg} \mathrm{ha}^{-1}\right)$ e secos $\left(619,41 \mathrm{~kg} \mathrm{ha}^{-1}\right)$ foram obtidos com as mais altas doses de fósforo $\left(81,7 \mathrm{~kg} \mathrm{ha}^{-1}\right)$. Mota et al. (2008), avaliando a biomassa de tansagem (Plantago major L.) com diferentes doses de fósforo e nitrogênio observaram que a adubação fosfatada elevou o número de folhas por planta e que as maiores doses dos nutrientes ( $400 \mathrm{~kg} \mathrm{ha}^{-1}$ de $\mathrm{P}_{2} \mathrm{O}_{5}$ e $80 \mathrm{~kg} \mathrm{ha}^{-1}$ de N) propiciaram maior área foliar e maior massa fresca $\mathrm{e}$ seca.

Em função do exposto, o objetivo deste

Rev. Bras. PI. Med., Botucatu, v.14, n.esp., p.235-241, 2012. 
trabalho foi avaliar o efeito da incorporação ao solo de cama-de-frango e de fósforo sobre o crescimento e a produção das plantas de fáfia.

\section{MATERIAL E MÉTODO}

O experimento foi desenvolvido entre outubro de 2009 e janeiro de 2011, no Horto de Plantas Medicinais - HPM, da Universidade Federal da Grande Dourados - UFGD, em Dourados-MS. O HPM tem altitude média de $452 \mathrm{~m}$; latitude 22011'43.7"S e longitude 5456'08.5"W; o clima, segundo a classificação de Köppen, é do tipo Cwa. O solo, originalmente sob vegetação de Cerrado, é um Latossolo Vermelho Distroférrico, de textura muito argilosa, e topografia plana. As características químicas do solo foram de 4,8 de $\mathrm{pH}$ em água $(1: 2,5)$;

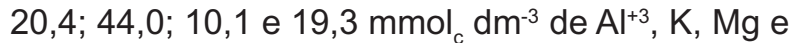
Ca; 4,62 $\mathrm{mg} \mathrm{dm}^{-3}$ de P; 33,9 $\mathrm{mmol}_{\mathrm{c}} \mathrm{dm}^{-3}$ de soma de bases; $64,1 \mathrm{mmol}_{\mathrm{c}} \mathrm{dm}^{-3}$ de capacidade de troca de cátions; $52,8 \%$ de saturação de bases e 34,0 $\mathrm{g} \mathrm{kg}^{-1}$ de matéria orgânica. Na parte física, os resultados da análise granulométrica do solo foram de $80 \mathrm{~g} \mathrm{~kg}^{-1}$ de areia grossa; $130 \mathrm{~g} \mathrm{~kg}^{-1}$ de areia fina, $160 \mathrm{~g} \mathrm{~kg}^{-1} \mathrm{de}$ silte e $630 \mathrm{~g} \mathrm{~kg}^{-1}$ de argila. Os atributos da cama-defrango, em g kg-1, foram de 218,10 de umidade total; 433,5 de matéria orgânica; 240,3 de $\mathrm{C}_{\text {total }} ; 43,7$ de Ca; 11,7 de $\mathrm{Mg} ; 8,5$ de $\mathrm{K} ; 31,5$ de $\mathrm{N}$ e 30,7 de P além de 7,14 de $\mathrm{pH} ; 0,55 \mathrm{mg} \mathrm{cm}^{-3}$ de densidade e 7,64 de relação $\mathrm{C} / \mathrm{N}$.

Foi estudada a fáfia, cultivada com cinco doses de cama-de-frango semidecomposta $(0,5,10$, 15 e $20 \mathrm{t} \mathrm{ha}^{-1}$ ), sem ou com o uso de fósforo (200 kg ha-1 de $\mathrm{P}_{2} \mathrm{O}_{5}$, na forma de superfosfato triplo), ambos incorporados ao solo antes do transplante das mudas. Os tratamentos foram arranjados em fatorial $5 \times 2$, no delineamento experimental blocos casualizados, com quatro repetições. As parcelas foram compostas por um canteiro com área total de 4,5 m² (1,5 m de largura $\times 3,0 \mathrm{~m}$ de comprimento) e área útil de $3,0 \mathrm{~m}^{2}$ (1,0 $\mathrm{m}$ de largura e 3,0 $\mathrm{m}$ de comprimento), contendo duas fileiras de plantas espaçadas de 0,50 m entre elas e 0,50 m entre plantas na fileira.

A propagação foi por semeadura indireta, em 27/10/2009, utilizando-se sementes colhidas de plantas cultivadas no HPM da UFGD. As mudas foram produzidas em bandejas de poliestireno de 128 células, com substrato Bioplant ${ }^{\circledR}$, mantidas em ambiente protegido com sombrite ${ }^{\circledR} 50 \%$, com irrigações diárias. Quando as plântulas atingiram cerca de $10 \mathrm{~cm}$ de altura, em 30/01/2010, foram transplantadas ao local definitivo.

O solo para o experimento foi preparado uma semana antes do transplantio, fazendo-se gradagem e levantamento de canteiros com duas passagens do rotoencanteirador. $\mathrm{Na}$ segunda passagem do implemento foi incorporada a cama-de-frango e o superfosfato triplo nas diferentes doses, nas parcelas correspondentes. Os tratos culturais na fase de campo compreenderam irrigações, utilizando-se o sistema de aspersão e capinas manuais.

Durante o ciclo de cultivo, foram avaliadas as alturas das plantas, a cada 21 dias, a partir dos 21 até 336 dias após o transplante - DAT. A colheita foi feita aos 360 DAT e consistiu no arranquio de quatro plantas inteiras em cada fileira estabelecidas na área útil de cada parcela. Depois, no laboratório de póscolheita, foram separadas as raízes, os caules e as folhas para determinação da massa fresca e área foliar em leitor de imagem com alta velocidade para folhas vegetais. Para medir o comprimento e o diâmetro das raízes, foi feita amostragem de seis raízes por parcela, sendo duas de tamanho grande, duas médias e duas pequenas e utilizou-se régua graduada em centímetros e paquímetro digital, respectivamente. Depois, obtiveram-se as médias dos comprimentos e diâmetros. Para a obtenção da massa seca, os materiais frescos das raízes, caules e folhas foram seccionados separadamente em fatias finas e distribuídos em sacos de papel. Posteriormente, os sacos foram colocados em estufa com circulação forçada de ar, a $60^{\circ} \pm 5^{\circ} \mathrm{C}$, até massa constante.

O material seco foi moído e digerido para a obtenção dos extratos. Os teores de $\mathrm{P}$ foram determinados pelo método da colorimetria de molibdovanadato; os de K, por fotometria de chama; os de $\mathrm{Ca}$ e Mg por espectrometria de absorção atômica e os de N, pelo método semimicro-Kjeldahl (Malavolta et al., 1997).

As médias dos dados obtidos foram submetidas à análise de variância e quando se verificou significância pelo teste $F$, foram ajustadas equações de regressão em função das doses de cama-de-frango e dias após o transplante, todos a $5 \%$ de probabilidade.

\section{RESULTADO E DISCUSSÃO}

As alturas das plantas foram influenciadas significativamente pela interação cama-de-frango e fósforo, sendo máximas $(138 \mathrm{~cm})$ sob $20 \mathrm{t} \mathrm{ha}^{-1} \mathrm{de}$ cama-de-frango, independente do uso de fósforo. Apesar disso, na presença de fósforo a altura máxima onde utilizou-se $5 \mathrm{t} \mathrm{ha}^{-1}$ de cama-de-frango foi semelhante àquela com o uso de $20 \mathrm{t} \mathrm{ha}^{-1}$ (Figura 1A). Esse resultado pode ter relação com a capacidade que a matéria orgânica tem de regular a temperatura do solo, retardar e reduzir a fixação do fósforo mineral e fornecer produtos da decomposição orgânica que favorecem o desenvolvimento da planta (Heredia Zárate et al., 2004; Kiehl, 2008). Da mesma forma, atua positivamente em relação às propriedades químicas do solo, onde age na melhoria da capacidade de troca de cátions, na redução do alumínio trocável,

Rev. Bras. PI. Med., Botucatu, v.14, n.esp., p.235-241, 2012. 

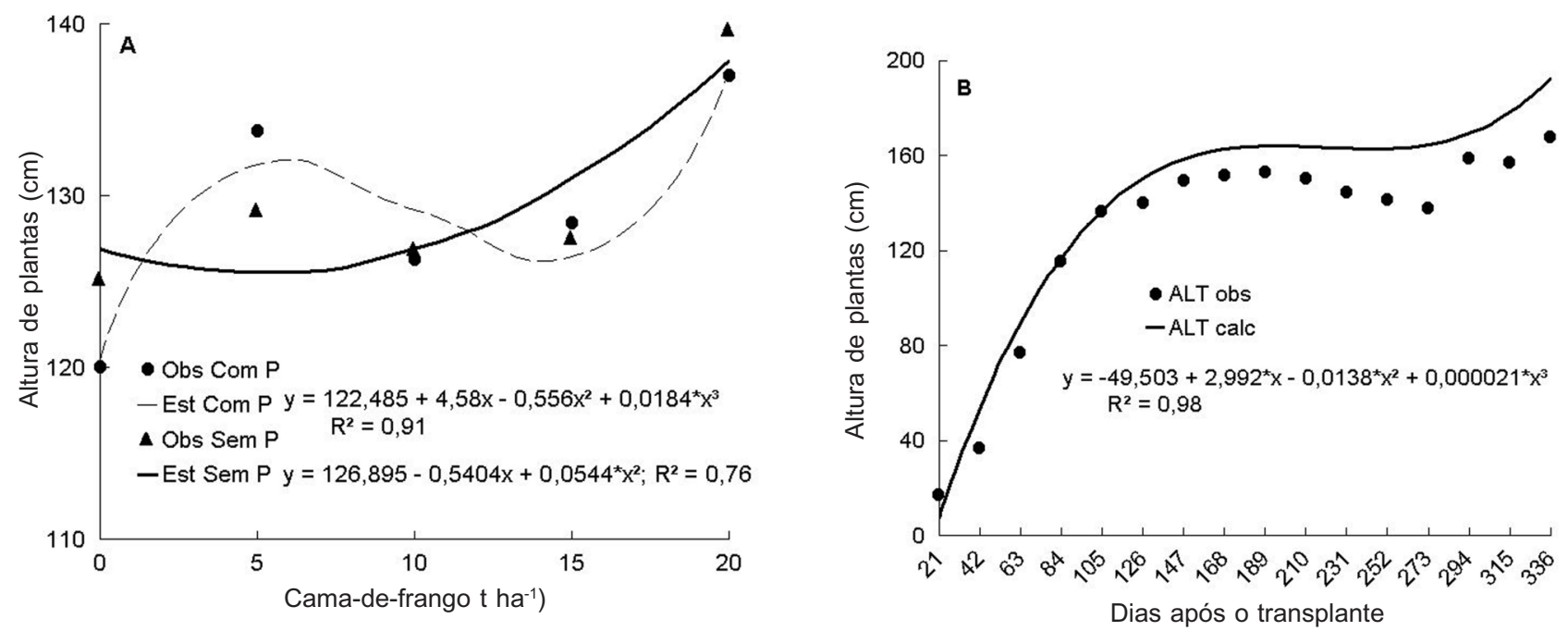

FIGURA 1. Altura de plantas de fáfia cultivadas com diferentes doses de cama-de-frango, com ou sem fósforo (A) e ao longo do ciclo de cultivo (B). Dourados, UFGD, 2011.

aumento de macro e micronutrientes disponíveis para as plantas, e na fixação de fosfato, onde a matéria orgânica do solo libera parte do N e P, promovendo aumentos na produção (Silva \& Mendonça, 2007). Vieira et al. (2003) citam que o uso de resíduos orgânicos deverá estimular, especialmente no início do ciclo da cultura, desenvolvimento adequado da parte aérea, em termos de altura e área foliar.

Ao longo do ciclo vegetativo (Figura 1B), as plantas de fáfia cresceram rapidamente até 105 dias após o transplante (DAT), depois permaneceram com as alturas praticamente estáveis. Houve novo aumento da altura a partir de 294 DAT, o que refletiu a rebrota da planta, com emissão de ramos novos a partir dos ápices, o que é característico da espécie. Segundo Taiz \& Zeiger (2004), os sistemas vegetais apresentam mecanismos de auto-regulação, baseando-se na capacidade de adaptação do organismo individual e das populações ou no equilíbrio das relações de interferência, como competição por nutrientes, água e luz, que influencia na produção e na partição de fotoassimilados.

A área foliar das plantas da fáfia foi influenciada pela interação cama-de-frango e fósforo, sendo que na presença de fósforo foi máxima (305 $\mathrm{cm}^{2}$ planta-1) com uso de $20 \mathrm{t} \mathrm{ha}^{-1}$ e na ausência de fósforo, reduziu linearmente com o aumento das doses de cama-de-frango (Figura 2). Segundo Novais \& Smyth (1999), a deficiência de fósforo é o fator mais limitante ao desenvolvimento das plantas em solos de cerrado, não só pelos baixos níveis naturais, mas também pela grande capacidade de fixação desses solos, como consequência da acidez e de elevados teores de óxidos de ferro e alumínio.

As produções de massas frescas e secas de folhas, de caules e de raízes foram influenciados significativamente pela interação cama-de-frango e

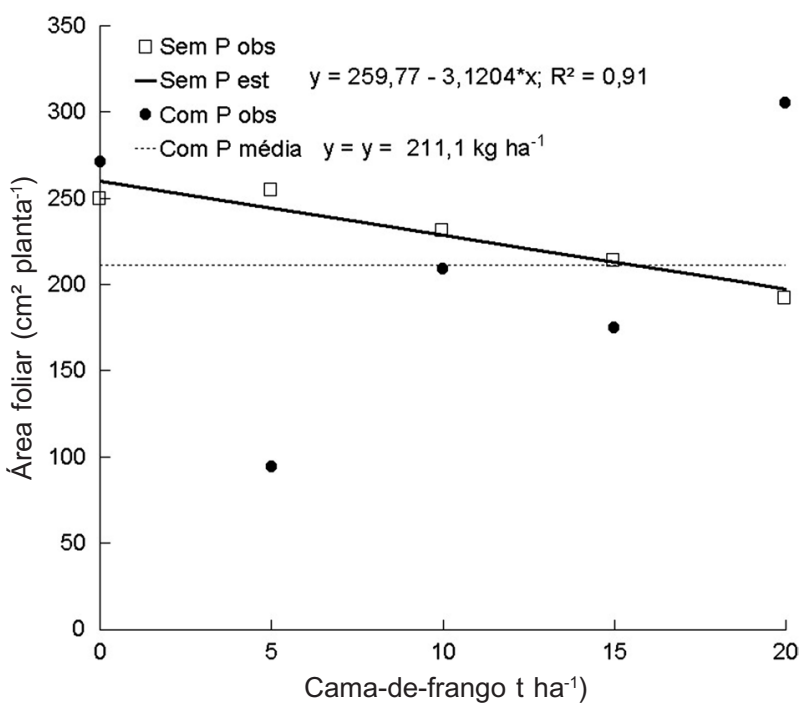

FIGURA 2. Área foliar de plantas de fáfia cultivadas com diferentes doses de cama-de-frango, com ou sem fósforo. Dourados, UFGD, 2011.

fósforo, com resposta quadrática para folhas e linear para caules e raízes. As maiores produções de massa fresca $\left(604,24 \mathrm{~kg} \mathrm{ha}^{-1}\right)$ e seca $(100,68$ $\left.\mathrm{kg} \mathrm{ha}^{-1}\right)$ de folhas foram obtidas com as doses de

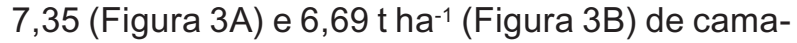
de-frango, sem o uso de fósforo. Para caules, as maiores produções de massas fresca $(7.930,40 \mathrm{~kg}$ $\left.\mathrm{ha}^{-1}\right)$ e seca $\left(2.167,65 \mathrm{~kg} \mathrm{ha}^{-1}\right)$ foram obtidas com a dose de $20 \mathrm{t} \mathrm{ha}^{-1}$ de cama-de-frango, com (Figura 4A) e sem o uso de fósforo (Figura 4B), respectivamente. Barboza et al. (2010), avaliando a produção da fáfia em monocultivo e nos policultivos com cravo-de-defunto (Tagetes erecta L.) e manjericão (Ocimum basilicum L.), sem e com incorporação de cama-de-frango semidecomposta, 
em dose de 10 tha- $^{-1}$, obtiveram produções de 10.280 $\mathrm{kg} \mathrm{ha}^{-1}$ de massa fresca e $3.210 \mathrm{~kg} \mathrm{ha}^{-1}$ de massa seca da parte aérea das plantas, independente do uso ou não da cama-de-frango. Esses resultados são diferentes aos encontrados neste trabalho $(8.534,64$ $\mathrm{kg} \mathrm{ha}^{-1}$ e $2.268,33 \mathrm{~kg} \mathrm{ha}^{-1}$, respectivamente), considerando-se parte aérea como sendo a soma de folhas e caules.

As maiores produções de massa fresca $\left(8.821,86 \mathrm{~kg} \mathrm{ha}^{-1}\right)$ (Figura 5A) e massa seca (2.500 $\mathrm{kg} \mathrm{ha}^{-1}$ ) (Figura 5B) de raízes foram obtidas com a dose de 20 t ha-1 $^{-1}$ de cama-de-frango, sem adição de fósforo. Barboza et al. (2010), avaliando a produção da fáfia em monocultivo e nos policultivos com cravode-defunto e manjericão, sem e com incorporação de cama-de-frango semidecomposta, em dose de 10 $\mathrm{t}$ ha $^{-1}$, observaram que nenhum dos tratamentos influenciou as produções de massas fresca $(10,02 t$ ha-1) e seca $\left(2,07 \mathrm{t} \mathrm{ha}^{-1}\right)$ da fáfia. Levantou-se a

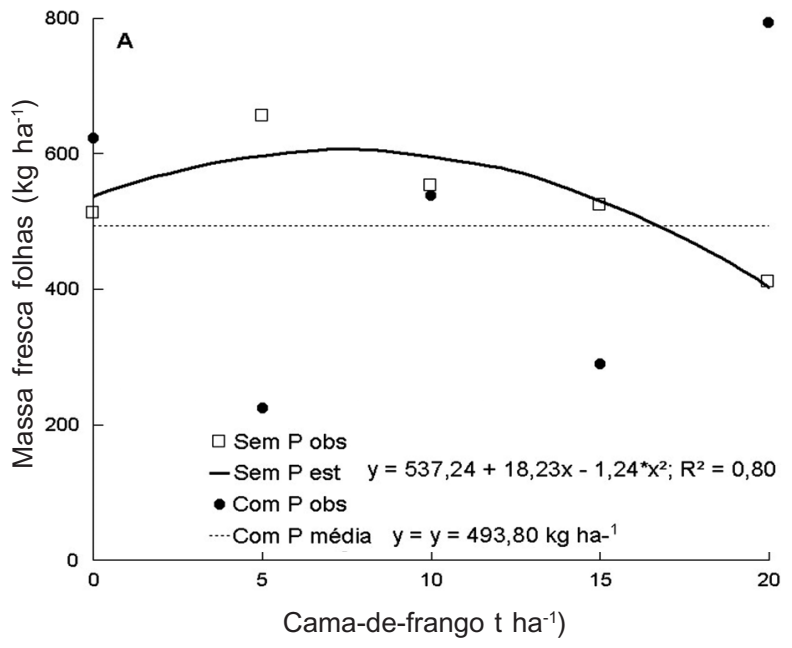

hipótese de que os efeitos benéficos do uso da camade-frango resultaram do fato de os resíduos orgânicos possibilitarem melhoria das propriedades físicas e químicas do solo, favorecendo a aeração e a capacidade de infiltração e armazenamento de água, permitindo assim, maior penetração e distribuição do sistema radicular. Por outro lado, os comprimentos e diâmetros médios das maiores raízes não variaram em função dos tratamentos e forma, em média, de $19,6 \mathrm{~cm}$ e $21,2 \mathrm{~mm}$, respectivamente.

Os teores de N, P e K das folhas da fáfia não foram influenciados pela aplicação da cama-defrango nem do fósforo no solo, sendo os teores médios de 8,60; 0,88 e 4,46 $\mathrm{g} \mathrm{kg}^{-1}$, respectivamente. Por outro lado, o teor de Ca cresceu linearmente com as doses de cama-de-frango (Figura 6A), independente da aplicação de fósforo, enquanto $\mathrm{Mg}$ apresentou teor mínimo de $3,36 \mathrm{~g} \mathrm{~kg}^{-1} \mathrm{com}$ o uso de $2,96 \mathrm{t} \mathrm{ha}^{-1} \mathrm{de}$ cama-de-frango mas aumentou até $5,12 \mathrm{~g} \mathrm{~kg}^{-1} \mathrm{com} \circ$

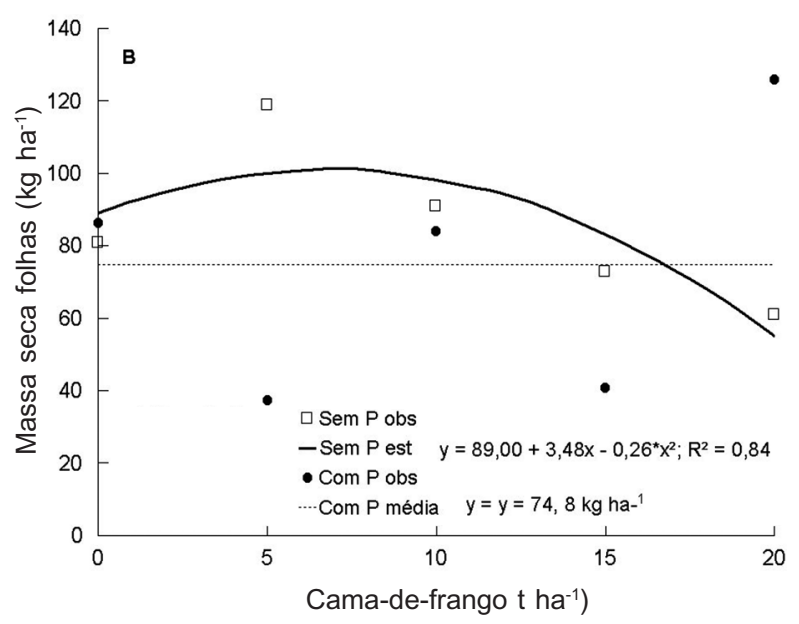

FIGURA 3. Massas frescas (A) e secas de folhas (B) de plantas de fáfia cultivadas com diferentes doses de camade-frango, com ou sem fósforo. Dourados, UFGD, 2011.
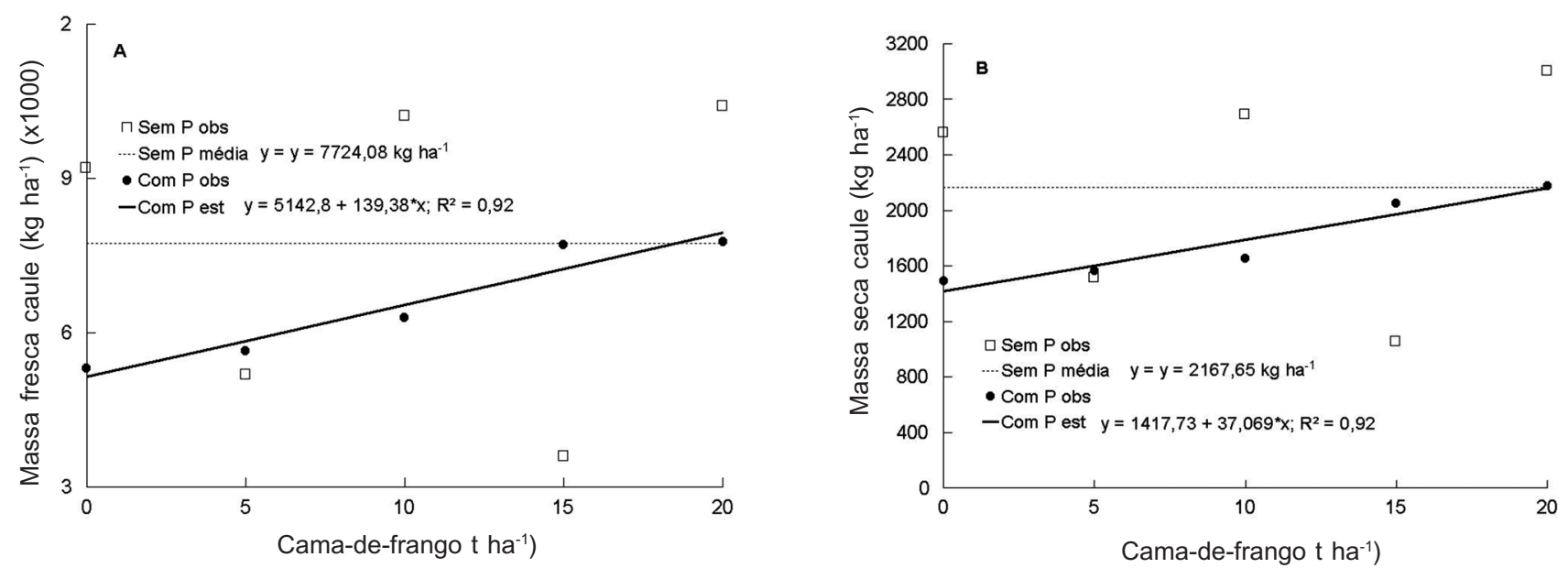

FIGURA 4. Massas frescas (A) e secas de caules (B) de plantas de fáfia cultivadas com diferentes doses de camade-frango, com ou sem fósforo. Dourados, UFGD, 2011. 

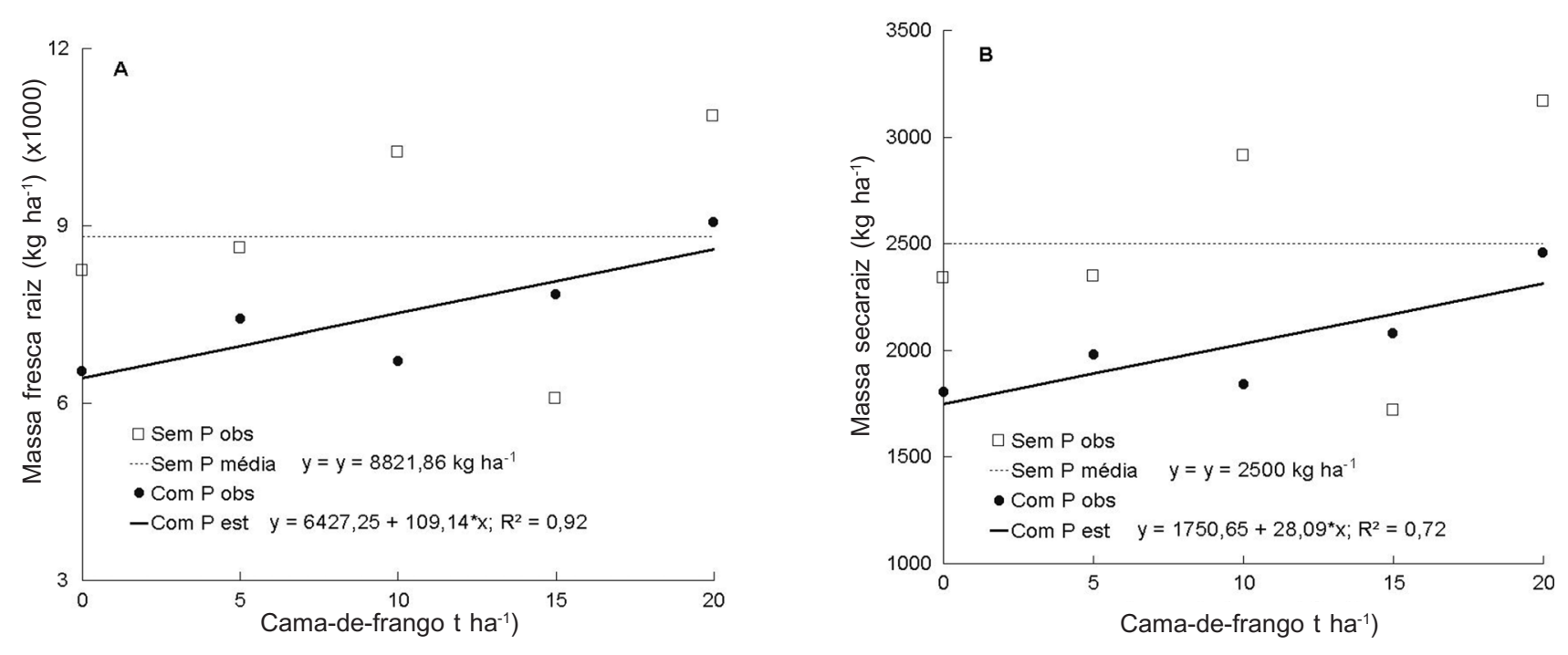

FIGURA 5. Massas frescas (A) e secas de raízes (B) de plantas de fáfia cultivadas com diferentes doses de camade-frango, com ou sem fósforo. Dourados, UFGD, 2011.
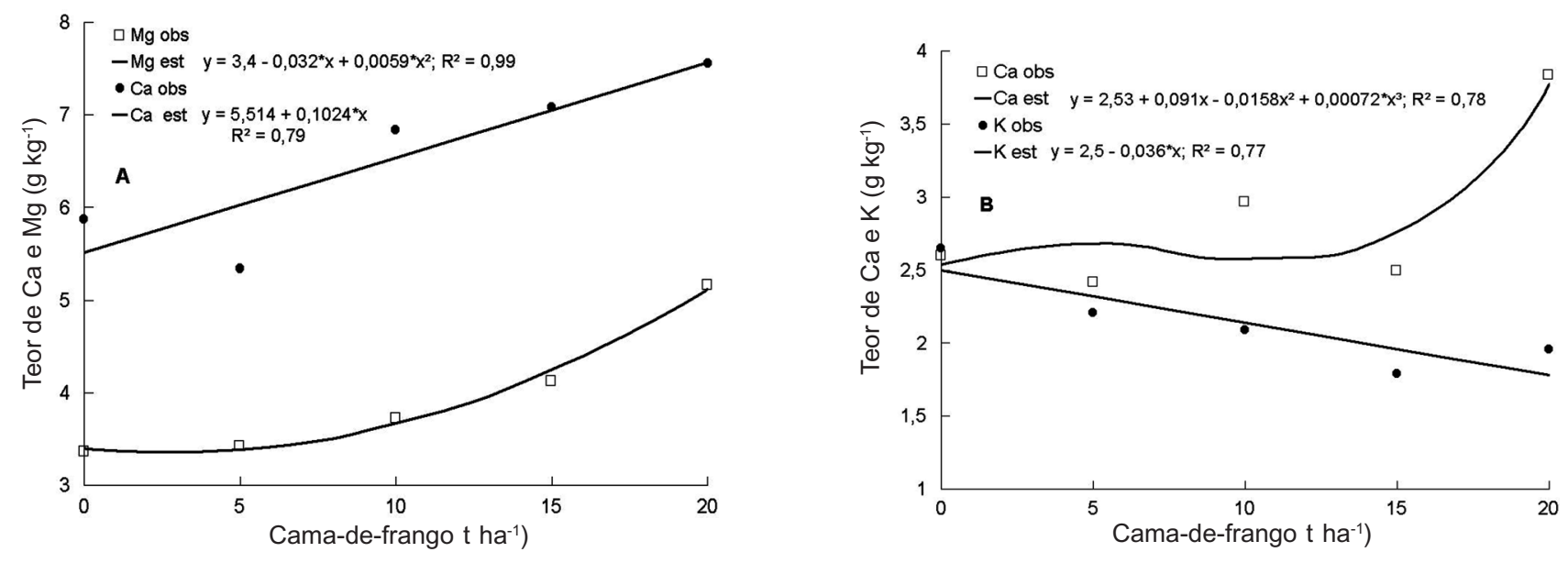

FIGURA 6: Teores de Ca e Mg nas folhas (A) e de Ca e $\mathrm{K}$ nas raízes (B) de plantas de fáfia cultivadas com diferentes doses de cama-de-frango. Dourados, UFGD, 2011.

uso de $20 \mathrm{t} \mathrm{ha}^{-1}$ (Figura 6A). Nas raízes, tal como nas folhas, os teores de $\mathrm{Ne} P$ não variaram em função do uso da cama-de-frango nem do fósforo, sendo as médias de $2,74 \mathrm{~g} \mathrm{~kg}^{-1} \mathrm{e} 0,27 \mathrm{~g} \mathrm{~kg}^{-1}$, respectivamente. O teor de $\mathrm{Mg}$ também não variou em função dos tratamentos, sendo a média de $0,96 \mathrm{~g} \mathrm{~kg}^{-1}$. Por outro lado, os teores de $\mathrm{K}$ e Ca variaram com as doses de cama-de-frango, sendo que o $\mathrm{K}$ reduziu linearmente e Ca apresentou maior teor na dose de 20 t ha-1 $^{-1}$ (Figura 6B).

Concluiu-se que para se obter maiores produções de massas frescas e secas de folhas e raízes, as plantas de fáfia devem ser cultivadas com cama-de-frango (20 tha $\left.{ }^{-1}\right)$ incorporada ao solo, sem necessidade de adição de fósforo.

\section{AGRADECIMENTO}

Ao $\mathrm{CNPq}$, pelas bolsas concedidas e à Fundect-MS, pelo apoio financeiro.

\section{REFERÊNCIA}

BARBOZA, V.C. et al. Phosphorus and chicken manure on development and yield of Tropaeolum majus $\mathrm{L}$. Revista Brasileira de Plantas Medicinais, v.8, n.esp., p.71-7, 2006.

BARBOZA, V.C. et al. Cama-de-frango em mono e policultivo de fáfia com cravo-de- defunto e manjericão. Horticultura Brasileira, v.28, n.3, p.348-54, 2010. CORREA JÚNIOR, C. et al. Sazonalidade na produção de raízes e teor de $\beta$-ecdisona em acessos de fáfia. Horticultura Brasileira, v.26, n.3, p.393-7, 2008.

GRACIANO, J.D. et al. Efeito da cobertura do solo com 
cama-de-frango semidecomposta sobre dois clones de mandioquinha-salsa. Acta Scientiarum: Agronomy, v.28, n.3, p.365-71, 2006.

HEREDIA ZÁRATE, N.A et al. Forma de adição ao solo da cama-de-frangos de corte semidecomposta para produção de taro. Pesquisa Agropecuária Tropical, v.34, n.2, p.111-7, 2004.

KIEHL, E.J. Adubação orgânica - 500 perguntas e respostas. Piracicaba: Editora Degaspari, 2008. $227 p$.

MAGALHÃES, P.M. Agrotecnologia para el cultivo de fáfia o ginseng brasileiro. In: MARTÍNEZ, J.V.; BERNAL, H.Y.; CÁCERES, A. (Eds.). Fundamentos de agrotecnología de cultivo de plantas medicinales iberoamericanas. Bogotá: CYTED, 2000. p.323-32.

MALAVOLTA, E. Manual de nutrição de plantas. São Paulo: Editora Agronômica Ceres. 2006. 638p.

MALAVOLTA E. et al. Avaliação do estado nutricional das plantas; princípios e aplicações. Piracicaba, POTAFOS, 1997. 319p.

MOTA, J.H. et al. Crescimento da espécie medicinal tansagem (Plantago major L.) em função da adubação fosfatada e nitrogenada. Ciência e
Agrotecnologia, v.32, n.6, p.1748-53, 2008.

NASCIMENTO, E.X. et al. Produção de biomassa de Pfaffia glomerata (Spreng.) Pedersen e Plantago major L. em cultivo solteiro e consorciado. Ciência e Agrotecnologia, v.31, n.3, p.724-30, 2007.

NOVAIS, R.F.; SMYTH, T.J. Fósforo em solo e planta em condições tropicais. Viçosa: UFV. 1999. 399p. SILVA, I.R.; MENDONÇA, E.S. Matéria orgânica do solo. In: NOVAIS, R.F. et al. (Eds.). Fertilidade do solo. Viçosa: SBCS. 2007. 1017p.

SILVA JÚNIOR, A.; OSAIDA, C.C. Ginseng-brasileiro novo estímulo para o campo e para o corpo. Agropecuária Catarinense, v.18, n.2, p.41-4, 2005. SOUZA, D.M.G.; LOBATO, E. Cerrado: correção do solo e adubação. Brasília: Embrapa Informação Tecnológica. 2004. 416p.

TAIZ, L.; ZEIGER, E. Fisiologia vegetal. 3.ed. Porto Alegre: Artmed, 2004. 719p.

VIEIRA, M.C. et al. Produção e renda de mandioquinhasalsa e alface, solteiras e consorciadas, com adubação nitrogenada e cama-de-frango em cobertura. Acta Scientiarum: Agronomy, v.25, n.1, p.201-8, 2003. 